\title{
La Publicidad del Registro Inmobiliario
}

\author{
Por el Dr. Jorge Ãvendaño Valdez
}

En el derecho moderno, el término publicidad, entendido como el principio que constituye el eje de los sistemas registrales, abarca un doble aspecto que es necesario estudiar: el de la legitimación registral y el de la fe pública del registro.

Se expresa con legitimación registral que los derechos y situaciones reales sobre inmuebles, por el hecho de su incorporación al registro, cumplidas las exigencias de la ley, quedan adscritos a su titular con una investidura de legitimidad que el registro ampara, frente a todos.

Pero la legitimación no es suficiente $y$, por lo tanto, se sanciona el principio de la fe pública del registro. Quien adquirió, de buena fe, de quien aparece como' dueño en el registro, a título oneroso, e inscribe el derecho adquirido, está protegido erga omnes. No importa que el enajenante no fuera en verdad dueño. Pudo haber vendido antes su derecho. Pero si esta transferencia no consta del registro, la posterior que se inscribe $y$ que se verificó a título oneroso, mantiene todo su valor.

La legitimación registral se refiere al título, al derecho que inviste al titular. El solo hecho de que este derecho ingrese al registro y sea sometido a la publicidad de éste, legitima el título, lo hace perfectamente válide, y los defectos de fondo y forma que pudiera tener quedan automáticamente saneados, en virtud de la publicidad. En cambio, la fe pública del registro es un efecto en relación a los terceros, no ya al título mismo. Su origen es idéntico: la publicidad. Pero va dirigido al adquirente que confía y acepta lo que el registro dice, precisamente conocedor de la fe pública de este último.

La publicidad sustantiva es, pues, la presunción de que el registro es exacto y al mismo tiempo íntegro. $E_{S}$ exacto porque expresa la realidad; es íntegro porque la agota.

Esta publicidad sustantiva debe distinguirse de la adietiver. Ácuélla comprende los ya estudiados conceptos de la legitimación y de la fe pública. Esta - la adjetiva- debe entenderse como lo posibilidad de que el público se entere del contenido de los libros. Se trata, en buena cuenta, de la publicidad que realiza, actualiza y hace posible la publicidad sustontiva. 
Se distingue entre publicidad constitutiva y declarativa. La primera se considera sustancialmente indispensable para la constitución de un determinado derecho. Tal ocurre en la transmisión de la propiedad en Alemania. Allí, la publicidad tiene el carácter de constitutiva, pues sin ella la transmisión no se ha efectuado. La publicidad es sólo declarativa cuando se refiere $\alpha$ actos o contratos ya perfectos y cuya falta da lugar a ciertos pequeños efectos que en ningún caso invalidan el acto o contrato previo.

Esta distinción de la publicidad en constitutiva $\mathrm{y}$ declarativa es análoga a otra: publicidad necesaria y no necesaria. Fs necesaria cuando interviene en el acto jurídico como elemento formador del mismo o al menos con el carócter de obligatoria para terceros. Es no necesaria cuando sólo pretende informar a todos los que no intervienen en el acto, pero sin causar efecto jurídico alguno.

La tendencia actual es dar a la publicidad los caracteres de constitutiva y necesaria.

Interesa ocuparse brevemente de la publicidad que nuestro registro inmobiliario brinda. El artículo 1052 de nuestro Código Civil dice a la letra: "Los actos que se ejecuten o los contratos que se otorguen por persona quie en el registro aparezca con derecho para ello, una vez inscritos, no se invalidarán en cuanto $\alpha$ los que con ella hubiesen contratado por título cneroso aunque se anule el derecho del otorgante en virtud de título anterior no inscrito o de causas que no resulten claramente del mismo registro".

Este dispositivo de nuestra ley regula la denominada "fe pública del registro", la misma que se encuentra involucrada dentro de la publicidad que, con fines metodológicos, llamamos sustantiva.

Aún cuando el profesor Lafaille (1) considera que este artículo 1052 no es prueba de derecho, ni siquiera una presunción de la existencia del mismo, somos de opinión que es un disposilivo que cimenta sobre bases bastante sólidas la publicidad sustantiva $y$ es en su virtud que el tercero de buena fe adquirente a título oneroso encuentra absolutamenie protegido el derecho que adquiere bajo la buena fe del regiziro. Efectivanente, son tres los presupuestos legales: a) que el otorgante apárezca en el registro con derecho inscrito; b) que el acto en virtud del cual se transmite ese derecho sea asímismo objeto de inscripción; y c) que ese acto trarlativo haya sido a título oneroso. Dados estos tres requisitos, el adquirente goza del beneficio de la fe pública registral. Esto es, la protección erga omnes de su adquisición con una presunción juris et de jure (sin admitirse prueba en contrario).

La Exposición de Mołivos del Códiço Civil dice que el artículo 1050 traduce la esencia del sistema adoptado y fija la verdadera inteligencia del tercero como titular del derecho que ampara el registro. $\AA$ nuestro juicio, su importancia no es extrema y más bien creemos que sólo reglamenta la prioridad de los que tienen derechos sobre un mismo inmueble, 
prioridad establecida en virtud de la fecha de inscripción àe los respectivos derechos. En cambio, el artículo 1052 sí es el eje de nuestra organización registral porque determina los alcances de la fe pública que el registro brinda, lo que es lo mismo, establece los efectos de la publicidad sustantiva. Al establecer los efectos de la publicidad, al mismo tiempo los limita: de la lectura del artículo se deduce, conirario sensu, que sólo si se anula el derecho del otorganie en virtud de causas que resulten claramente del mismo registro no se encuentra garantido el derecho del tercero adquirente $a$ título oneroso.

Mucho se ha discutido sobre el significado de esa frase "de causas que no resulten claramente del mismo registro". Vamos a ilustrar nuestro criterio al respecto con un ejemplo. Juan es poseedor por más de treinta años de un inmueble que no se encuentra registrado y del cual no tiene títulos comprobativos de su dominio. Forma títulos supletorios e inscribe su derecho de propiedad. De inmediato, vende a Jorge, quien adquiere a título oneroso y bajo la fe del registro, en el que aparece que el propietario del inmueble es Juan. Jorge inscribe su adquisición. Pedro interpone demanda contra Jorge para reivindicar parie del bien, puesto que él afirma ser el verdadero propietario en razón de que los títulos supletorios adolecen de nulidad; pues él, siendo colindante, no fué citado en el pro. ceso judicial, usurpándose así su derecho sobre parte del inrnueble que ahora oparece íntegramente a nombre de Jorge. Sólo podrá declararse fundada esia demanda si de los mismos asientos de dominio apareciera la causal de nulidad de los títulos supletorios. De lo contrario, Jorge gozaría de su condición de aảquirente a título oneroso bajo la fe del registro Y, por tanto, estaría protegido contra la evicción.

Nuestra jurisprudencia ha considerado, ademáx, en ciertos casos: 1) Que no cabe protección del adquirente cuando la nulidad no es perceptible en los libros del registro, pero sí en los títuios del bien. Esta posición va en contra del texto del artículo 1052 y no esté de acuerdo con principios básicoś del Derecho Registral. Se debe tender a que el examen de las titulaciones de los inmuebles se haga sólo en los asientos de dominio. En casos como éste, en que la misma ley da excepcionalmente preferencia a la inscripción sobre el título, nuesiros Tribunales deberícn respetar el texto de la disposición legal. La actitud de nuestra Corte Suprema se explica si se tienen en cuenta las múltiples deficiencias de nuestro siste- $m a$ registral. 2) Que es menester añadir al artículo 1052, para que proceda la defensa del tercero, la buena fe de éste, es decir su ignorancia de que la situación registrada adolece de algún vicio. Es lógico que nuestro Supremo Tribunal haya tratado de agregar este requisito al artículo 1052, puesto que es consecuencia de la onterior posición que da preferencia a los títulos sobre los asientos de dominio. Es claro que si el adquirente examina los títulos y en ellos descubre una causal de nulidad que no cparece claramente del registro y aún así adquiere, pretendiendo ccogerse al 1052 para gozar de la protección que éste acuerda, no está procediendo con buena fe. Sin embargo, la Corte está distinguiendo donde la ley no distingue. 
La misma razón que nos indujo a no aceptar el preiendido requisito del exámen de los títulos, nos hace pronunciarnos en el sentido de que en estricta interpretación legal no cabe investigar la buena fe del tercero. Ello puede justificarse entro nosotros por razones prácticas y sólo admitiendo - como parece hacerlo la Corte Suprema- los defectos saltantes de que adolece nuestro registro, uno de los cuales es el de la no legitimación del títuio inscrito.

En cuanto a la publicidad adjetiva que nuestro registro brinda, es elogiable que la manifestación de los libros no esté restringida como en la legislación alemana a los que tengan un "interés justificado" por examinar los asientos.

La expedición de certificados por parte de los Registradores tampoco está limitada a determinadas personas. El artículo 115 del Reglamento de las Inscripciones se refiere a la petición de "cualquier interesado".

Pero, en cambio, el artículo 126 del mismo Reglamento es, a nuestro parecer, contrario a todo principio registral. Dice el artículo: "Cuando los certificados de que habla el artículo 114 (literales, compendiosos, incluyendo dentro de éstos a los de gravámenes) no sean conformes con los asientos a que se refieren, se estará a lo que de éstos resulte, salvo la acción del perjudicado para exigir del Registrador culpable la correspondiente indemnización". Citaremos al respecto las palabras del doctor Lizardo Alzamora Silva (2):

"Aceptar que puedan equivocarse los nombres o trocarse las paiabras es deplorable en un Reglamento de legislación inmobiliaria. Si se quiere que la confianza pública repose en la certificación del registro, si se pretende, según la ley, dar seguridades a los contratantes sobre la propiedad inmueble, es preciso rodear los actos de la institución que vela por tan alios intereses, de procedimientos que descarten la posibilidad de errores, $\mathrm{y}$, en el caso improbable de haberse cometido, debe indemnizarse los daños".

Hemos visto, al hacer el examen de los artículos 1050 y 1052 del Código Civil, que nuestro Registro de la Propiedad defiende el derecho dei tercero, el que, como sabemos, debe reunir determinacios recivisios, unos do orden legal y ctros añadidos por la jurisprudencia. Pues bien, es a ese tercero, en cuyo beneficio funciona la institución registral, que se está perjucicando con lo establecido en el artículo 126 del Reglamento de las Inscripcicnes. Es el "futuro tercero", el adquirente, quien generalmente se ve perjudicado por un certificado que no corresponde a lo que realmente aparece en las libros. $Y$, sin embargo, el Registro no lo protege. Este artículo 126 del Reglamento constutuye la quiebra de nuestro híbrido sistema inmobiliario. No puede haber seguridad en la contratación sobre inmuebles si la institución llamada a otorgarla no concede crédito absoluto e irrestricto a los certificados que expide. Se puede aceptar que la inscripción no sanee el título; puede tolerarse que la inscripción no sea constitutivo de los derechos reales, ni siquiera prueba plena de los mismos; pero lo inodmisible es que la protección del tercero y la relctiva seguridad en el crédito territorial -garantías ambas y únicas para las cuales existe nuestro Registro de la 
Propiedad- no estén contempladas aceptablemente en lo que al mérito de los certificados se refiere.

La posición legal debería ser totalmente opuesta: en caso de disconformidad entre el certificado y el asiento, debe estarse a lo que aparezca de aquél. Esta es la solución doctrinaria, que por lo demás es congruente. Se nos objetará de inmediato: ¿quién paga entonces las indemnizaciones que puedan deberse por concepto de errores? Para ello, hay dos soluciones de tipo práctico que deben funcionar conjuntas: la primera, esbozada por el doctor Alzamora: rodear los actos del registro de procedimientos que descarten la posibilidad de error; la segunda, crear un fondo destinado a indemnizar a los perjudicados, el que podría constituirse sobre la base de un cobro adicional de derechos por la expedición de todo tipo de certificados. No pretendemos la implantación de un sistema tipo Torrens. Nuestro fondo funcionará únicamente en caso de daños derivados de errores en los certificados, no así tratándose de los ocasionados por inscripciones erróneas.

(1) Lafralle, Héctor, Derecho Civil. Buenos Aires: Ediar S. A., 1947, tomo V.

(2) Alzamora Silva, Lizardo, La Inscripción inmobiliaria. Tesis para graduarse de Bachiller en Derecho. Lima: Librería e Imprenta Gil, 1923. 